\title{
ANALISIS FAKTOR YANG MEMPENGARUHI PERILAKU KONSUMEN DALAM KEPUTUSAN MEMBELI RUMAH SEDERHANA DI PERUMAHAN PURIMAS KELURAHAN BENTIRING KECAMATAN MUARA BANGKA HULU KOTA BENGKULU
}

\author{
Markoni \\ Dosen Fakultas Ekonomi Unihaz.
}

\begin{abstract}
This study aims to determine the effect of Price, House Design, location, available facilities, and Housing Environment simultaneously on consumer behavior in the decision to buy a simple house in Purimas Housing, Bentiring Sub-District, Bengkulu City Muara Bangka Hulu Subdistrict, and which factors have partial influence more dominant. The population of this study was buyers of simple houses in Purimas Housing, Bentiring Sub-District, Muara Bangka Hulu Sub-District, bengkulu City. Sampling uses incidental sampling techniques. Data collection uses questionnaires and literature. Primary data and secondary data collected, processed and analyzed by multiple correlation methods and multiple linear regression methods. Price Factors, House Design, location, facilities available, and Housing Environment simultaneously have a very strong influence on consumer behavior in simple home buying decisions in Purimas housing as indicated by the multiple correlation coefficient (R) 0.929, with the contribution of variations to the fifth change in the independent factor for consumer behavior by $86.3 \%$. From the equation $\mathrm{Y}=0.079+0.267 \mathrm{X} 1+0.202 \mathrm{X} 2+0.175 \mathrm{X} 3+$ $0.192 \mathrm{X} 4+0.218 \mathrm{X} 5+\mathrm{e} 1$

By comparing the magnitude of the Regression coefficient of each Price Factor, Design, Location, Available Facilities and environment, it is known that the more dominant factor influencing consumer behavior is the price of the house, then followed by the environment, design and then available facilities and housing locations. Hypothesis Test Results on multiple correlation coefficients, as well as Hypothesis Tests on regression coefficients of all the Factors studied show that there is a significant effect of Price Factors, House Design, location, available Facilities, and Housing Environment both simultaneously and partially significantly influence towards consumer behavior in the decision to buy a simple house in Purimas Housing, Bengkulu City. Based on the analysis, the researcher suggested the developer company to maintain prices, create new designs that follow market tastes, and improve housing facilities.
\end{abstract}

Key Words: Price, Design, Location, Available Facilities, Environment, Consumer Behavior 


\section{PENDAHULUAN}

Seiring dengan pertumbuhan penduduk yang disertai dengan pertumbuhan Pendapatan khususnya di Provinsi Bengkulu, maka permintaan akan Rumah baik untuk memenuhi kebutuhan Pokok manusia menurut fungsinya, seperti kebutuhan tempat berteduh dari teriknya panas matahari ataupun berlindung dari udara dingin dan hujan, kebutuhan untuk tempat berlindung dari gangguan keamanan dan kejahatan atau gangguan binatang buas, sebagai tempat beristirahat melepas rasa lelah dan kepenatan, dan sebaginya. Permintaan akan rumah dalam perkembangannya dimasa modern sekarang ini sudah berkembang juga untuk keperluan Investasi, baik untuk di jual kembali, ataupun untuk disewakan atau hanya sekedar alat penyimpan kekayaan.

Peningkatan akan Rumah yang selalu meningkat seiring dengan pertambahan jumlah penduduk dan peningkatan pendapatan tersebut di satu sisi, dan di sisi lain ketersediaan lahan untuk pemenuhan kebutuhan akan rumah tersebut semakin terbatas, dan harganya juga semakin mahal. Kondisi ini merupakan fenomena yang terjadi di daerah perkotaan. Fenomena pemukiman ini disatu sisi merupakan permasalahan bagi penduduk perkotaan, tetapi di lain pihak memberikan peluang bagi perusahaan pengembang property untuk mengembangkan usahanya.

Persoalannya adalah apa yang harus dilakukan oleh perusahaan pengembang property agar dapat memanfaatkan peluang tersebut ?. Setiap perusahaan pengembang property harus dapat mengetahui dan memahami perilaku konsumen dalam keputusan pembelian. Beberapa factor yang menjadi pertimbangan bagi kosumen dalam membeli rumah tersebut antara lain Harga, Desain Rumah, Lokasi, Fasilitas yang tersedia, serta Lingkungan Perumahan, dan masih banyak lagi yang lain.

Faktor harga akan menjadi salah satu pertimbangan bagi seorang pembeli atau konsumen, karena masalah harga terkait dengan daya beli atau kemampuan seseorang calon konsumen untuk membeli rumah tersebut. Sedangkan Desain Rumah, Lokasi, Fasilitas yang tersedia, serta Lingkungan Perumahan, turut mempengaruhi perilaku konsumen karena terkait dengan selera seseorang. Bagi seseorang yang pendapatannya rendah tentu saja factor harga lebih dominan dari pada factor lainnya, tetapi bagi seseorang yang pendapatannya cukup tinggi, maka factor factor yang terkait dengan selera seperti Desain Rumah, lokasi, Fasilitas yang tersedia, serta Lingkungan Perumahan, dan sebagainya tentu saja akan mendapat perhatian yang tidak kalah pentingnya dari pada harga, bahkan mungkin lebih dominan dari pada harga.

Dari uraian di atas penelitian ini akan mengambil Tofik Analisis Faktor yang Mempengaruhi Perilaku Konsumen Dalam Keputusan Membeli Rumah Sederhana di Perumahan Purimas Kelurahan Bentiring Kecamatan Muara Bangka Hulu Kota Bengkulu.

\section{A. Rumusan Masalah}

Permasalahan yang dirumuskan untuk diangkat dalam penelitian ini adalah :

1. Apakan Harga, Desain Rumah, Lokasi, Fasilitas yang tersedia, serta Lingkungan Perumahan secara simultan berpengaruh terhadap perilaku konsumen dalam keputusan membeli rumah sederhana di Perumahan Purimas Kelurahan Bentiring Kecamatan Muara Bangka Hulu Kota Bengkulu? 
2. Faktor manakah di antara Harga, Desain Rumah, Lokasi, Fasilitas yang tersedia, serta Lingkungan Perumahan yang secara parsial lebih dominan pengaruhnya terhadap perilaku konsumen dalam keputusan membeli rumah sederhana di Perumahan Purimas Kelurahan Bentiring Kecamatan Muara Bangka Hulu Kota Bengkulu?

\section{B. Tujuan Penelitian}

Sejalan dengan permasalahan penelitian yang dirumuskan tersebut di atas, maka tujuan dari penelitian ini adalah:

1. Untuk mengetahui pengaruh Harga, Desain Rumah, Lokasi, Fasilitas yang tersedia, serta Lingkungan Perumahan secara simultan terhadap perilaku konsumen dalam keputusan membeli rumah sederhana di Perumahan Purimas Kelurahan Bentiring Kecamatan Muara Bangka Hulu Kota Bengkulu

2. Untuk mengetahui pengaruh manakah yang lebih dominan di antara Harga, Desain Rumah, Lokasi, Fasilitas yang tersedia, serta Lingkungan Perumahan yang secara parsial terhadap perilaku konsumen dalam keputusan membeli rumah sederhana di Perumahan Purimas Kelurahan Bentiring Kecamatan Muara Bangka Hulu Kota Bengkulu?

\section{Tinjauan Pustaka}

\section{Harga}

Menurut Philip Kotler, pengertian harga adalah sejumlah uang yang dibebankan ke suatu produk atau layanan jasa. Artinya, harga adalah jumlah nilai yang harus dibayar konsumen demi memiliki atau mendapatkan keuntungan dari sebuah produk barang ataujasa.(https://www.maxmanroe.com/vid/bisnis/pengertian-harga.html). Sedangkan menurut Effendi (1998:185) Harga adalah suatu nilai yang dinyatakan dalam bentuk rupiah atau dalam bentuk moneter lain guna memperoleh manfaat yang ditimbulkan dan oleh barang maupun jasa.

\section{Desain}

Menurut The American Collage DictionaryDesain adalah garis besar, sketsa, rencana, seperti dalam kegiatan seni, bangunan, gagasan tentang mesin yang akan diwujudkan.(http://www.haidesain.com/2017/11/pengertian-desainmenurut-para-ahli.html)

\section{Lokasi}

Menurut Peraturan Mendagri nomor 3 tahun 1987, Areal Tanah (Lokasi) perumahan adalah suatu lingkungan pemukiman yang dilengkapi dengan prasarana lingkungan, fasilitas umum dan fasilitas social yang diperlukan oleh masyarakatpenghuni lingkungan perumahan. 


\section{CREATIVE RESEARCH MANAGEMENT JOURNAL-CRMJ}

\section{Fasilitas yang tersedia}

Menurut Suharsimi Arikunto, Fasilitas adalah segala sesuatu hal yang dapat memudahkan dan memperlancar pelaksanaan segala sesuatuusaha (http://www.pengertianmenurutparaahli.net/pengertian-fasilitas/)

\section{Lingkungan}

Dalam Undang-Undang Nomor 23 Tahun 1997 tentang Pengelolaan Lingkungan Hidup menyebutkan pengertian lingkungan adalah kesatuan ruang dengan semua benda, daya, keadaan dan makhluk hidup termasuk manusia dan prilakunya yang mempengaruhi kelangsungan hidup dan kesejahteraan manusia serta makhluk hidup lain(http://seputarpengertian.blogspot. com/ 2017/05/pengertianlingkungan-serta-jenisnya.html)

\section{Perilaku Konsumen}

Menurut The American Marketing Association Perilaku konsumen adalah proses membagai interaksi dinamis dari pengaruh dan kesadaran, perilaku dan lingkungan dimana seseorang melakukan pertukaran aspek kehidupannya. (http://ciputrauceo.net/blog/2015/6/11/perilaku-konsumen)

Menurut Schiffman dan Kanuk Perilaku konsumen adalah suatu proses yang dilalui oleh seorang pembeli dalam mencari, membeli, menggunakan, mengevaluasi serta bertindak pada konsumsi produk dan jasa, maupun ide yang diharapkan dapat memenuhi kebutuhan seseorang tersebut. (http://ciputrauceo. net/blog/2015/6/11/perilaku-konsumen)

\section{Kerangka Analisis}

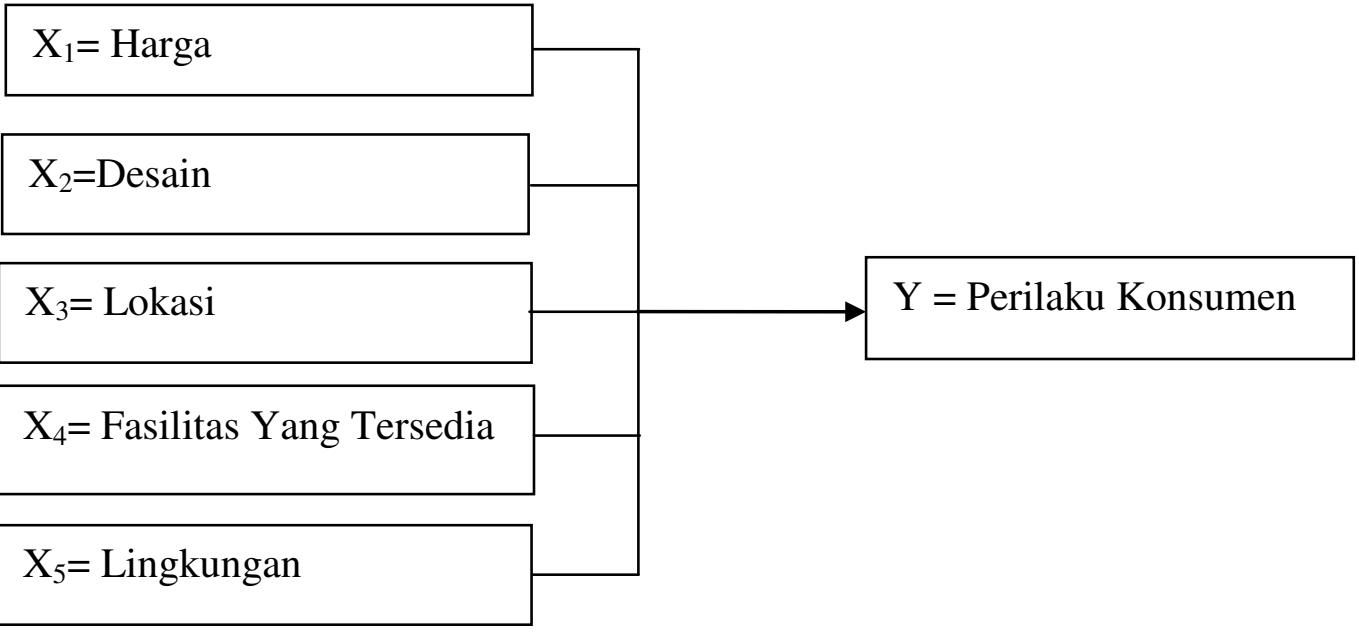


Untuk mengetahui pengaruh dari Faktor Harga, Desain, Lokasi, Fasilitas yang tersedia dan Lingkungan dengan Faktor Perilaku Konsumen dalam Keputusan Membeli Rumah Sederhana di Perumahan Purimas Kelurahan Bentiring Kecamatan Muara Bangka Hulu Kota Bengkulu dilakukan baik secara parsial maupun secara Simultan, serta di dianalisis Faktor mana yang paling dominan dalam mempengaruhi Perilaku Konsumen tersebut.

\section{E. Hipotesis}

Bahwa Harga, Desain, Lokasi, Fasilitas yang tersedia dan Lingkungan berpengaruh terhadap Perilaku Konsumen dalam Keputusan Membeli Rumah Sederhana di Perumahan Purimas Kelurahan Bentiring Kecamatan Muara Bangka Hulu Kota Bengkulu

\section{F. Depinisi Operasional}

1. Harga adalah tanggapan responden terhadap besaran nilai rupiah rumah yang ditetapkan oleh pihak pengembang perumahan Purimas.

2. Desain adalah tanggapan responden terhadap desain rumah di perumahan Purimas.

3. Lokasi adalah tanggapan responden terhadap lokasi perumahan Purimas.

4. Fasilitas adalah tanggapan responden terhadap fasilitas rumah dan fasilitas perumahan yang disediakan oleh pengembang perumahan.

5. Lingkungan adalah tanggapan responden terhadap lingkungan disekitar perumahan Purimas.

\section{G. Metode Penelitian}

1. Jenis dan Sumber Data

Penelitian ini menggunakan Data Primer dan Data Sekunder.Data Primer diperoleh dengan menyebarkan Kuisioner kepada Responden, sedangkan data Sekunder didapatkan dari berbagai literature dan hasil penelitian terdahulu.

2. Populasi dan Sampel

Populasi dalam penelitian ini adalah Konsumen atau pembeli dari rumah di Perumahan Purimas Kelurahan Bentiring Kecamatan Muara Bangka Hulu Kota Bengkulu yang keselurukannya berjumlah 500 Unit, yang kesemuanya type 36. Karena populasi tersebut bersifat relatif Homogin, maka Jumlah sampel diambil hanya $10 \%$ dari populasi tersebut yaitu sebanyak 50 Orang, yang diambil secara insidental (Insidental Sampling). Untuk memudahkan penelitian maka Sampel yang dipilih adalah responden yang sudah menempati Rumah tersebut, dan berada di rumah pada saat peneliti mengumpulkan data.

3. Teknik pengumpulan Data

Pengumpulan Data dalam penelitian ini menggunakan Kuisioner yang disebarkan kepada Responden yang dijadikan Sampel.Masing-masing 


\section{CREATIVE RESEARCH MANAGEMENT JOURNAL-CRMJ}

pertanyaan dilingkapi dengan 5 alternatif jawaban. Pemberian Skor untuk pengolahan data menggunakan skala likert lima poin.

\section{Teknis Analisis}

Data yang telah dikumpulkan melalui penyebaran kuisioner, dan telah pula diolah, kemudian dilanjutkan dengan analisa data. Dalam melakukan analisa data ini digunakan metode Regresi Liner Berganda dan Metode Korelasi Berganda, dan Perhitungannya menggunakan program Statistik SPSS.

Dimana:

$$
\mathrm{Y}=\mathrm{a}+\mathrm{b}_{1} \mathrm{X}_{1}+\mathrm{b}_{2} \mathrm{X}_{2}+\mathrm{b}_{3} \mathrm{X}_{3}+\mathrm{b}_{4} \mathrm{X}_{4}+\mathrm{b}_{5} \mathrm{X}_{5}+\mathrm{e}_{\mathrm{i}}
$$

$\mathrm{Y}=$ Perilaku Konsumen dalam Keputusan Membeli Rumah sederhana di Perumahan Purimas

$\mathrm{X}_{1}=$ Harga

$\mathrm{X}_{2}=$ Desain

$\mathrm{X}_{3}=$ Lokasi

$\mathrm{X}_{4}=$ Fasilitas yang tersedia

$\mathrm{X}_{5}=$ Lingkungan Perumahan

$\mathrm{a}=$ Konstanta

$\mathrm{b}_{1}, \mathrm{~b}_{2}, \mathrm{~b}_{3}, \mathrm{~b}_{4}, \mathrm{~b}_{5}=$ Koefisien Regresi dari masing masing Faktor $\mathrm{e}_{\mathrm{i}}=$ Faktor pengganggu di luar model

Alat Uji statistic untuk hubungan Parsial dengan menggunakan Uji t dan Uji hubungan Simultan menggunakan Uji F dengan $\alpha=0,05$

\section{Analisis}

Dari hasil pengolahan data sebagaimana tertera pada print out SPSS diperoleh Koefisien Korelasi berganda dan Koefisien Diterminasi berganda sbb:

\begin{tabular}{|l|r|r|r|r|}
\hline \multicolumn{5}{|c|}{ Model Summary } \\
\hline Model & R & R Square & Adjusted R Square & $\begin{array}{c}\text { Std. Error of the } \\
\text { Estimate }\end{array}$ \\
\hline 1 & $.929^{\mathrm{a}}$ & .863 & .848 & .44606 \\
\hline \multicolumn{7}{|l|}{ a. Predictors: (Constant), Lingkungan, Lokasi, Fasilitas, Desain, Harga } \\
\hline
\end{tabular}

Nilai koefisien korelasi berganda (R) yang dihasilkan sebesar 0,929. Hasil ini menunjukkan bahwa terdapat hubungan yang sangat erat dan searah antara harga, desain, lokasi, fasilitas, dan lingkungan secara bersama sama dengan perilaku konsumen dalam keputusan membeli rumah sederhana perumahan Purimas Kelurahan Bentiring Kota Bengkulu. Bila terjadi perubahan, baik salah satu maupun kelima Faktor tersebut secara bersama-sama, maka akan diikuti oleh perubahan pada perilaku konsumen dalam keputusan membeli rumah sederhana dengan arah yang sama, baik perubahan yang bersifat bertambah ataupun perubahan yang bersifat berkurang. 


\section{CREATIVE RESEARCH MANAGEMENT JOURNAL-CRMJ}

Nilai R-square yang dihasilkan sebesar 0,863 , hasil ini menunjukkan bahwa harga, desain, lokasi, fasilitas, dan lingkungan secara simultan memberikan kontribusi terhadap variasi perubahan perilaku konsumen dalam keputusan membeli rumah sederhana di Perumahan Purimas sebesar 86,3\%

Keeratan hubungan yang ditunjukkan oleh besaran nilai Koefisien Korelasi Berganda (R) tersebut masih harus diuji untuk melihat Signifikansi dari hubungan antar variabel yang diteliti. Untuk maksud tersebut dapat dilihat dari Tabel print out SPSS sbb:

\begin{tabular}{|l|l|r|r|r|r|c|}
\hline \multicolumn{7}{|c|}{ NNOVA $^{\mathbf{a}}$} \\
\hline \multirow{2}{*}{ Model } & $\begin{array}{c}\text { Sum of } \\
\text { Squares }\end{array}$ & \multicolumn{1}{c|}{ df } & Mean Square & F & \multicolumn{1}{c|}{ Sig. } \\
\hline \multirow{3}{*}{1} & Regression & 55.326 & 5 & 11.065 & 55.613 & $.000^{\mathbf{b}}$ \\
\cline { 2 - 7 } & Residual & 8.754 & 44 & .199 & & \\
\cline { 2 - 6 } & Total & 64.080 & 49 & & & \\
\hline
\end{tabular}

a. Dependent Variable: Perilaku Konsumen

b. Predictors: (Constant), Lingkungan, Lokasi, Fasilitas, Desain, Harga

Untuk melihat besarnya pengaruh perubahan setiap variable indipenden terhadap variable dipenden, digunakan Analisis Regresi Berganda yang hasil print out SPSS sbb:

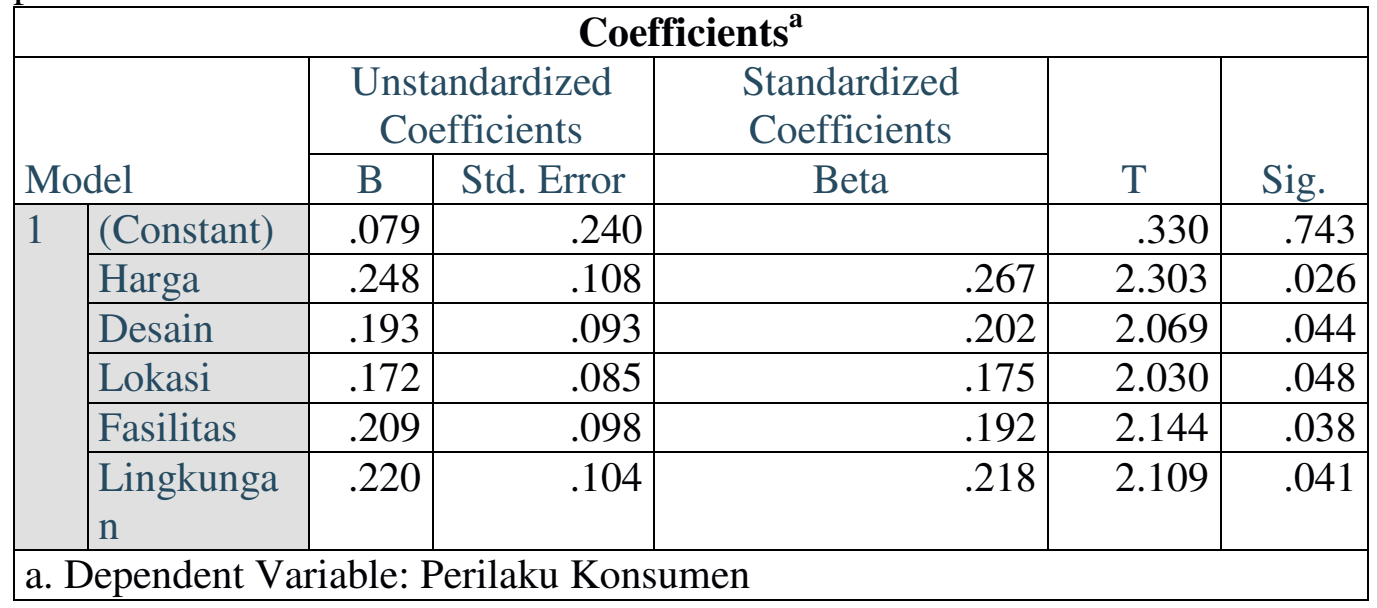

Dari Tabel tersebut di atas, diketahui persamaan regresi berganda yang dihasilkan adalah sebagai berikut:

$$
Y=0,079+0,267 X_{1}+0,202 X_{2}+0,175 X_{3}+0,192 X_{4}+0,218 X_{5}+e_{1}
$$

Berdasarkan persamaan tersebut diketahui nilai konstanta sebesar 0,079. Nilai konstanta tersebut menunjukkan bahwa terdapat konsumen yang dalam mengambil keputusan membeli rumah di perumahan Purimas perilakunya tidak 


\section{CREATIVE RESEARCH MANAGEMENT JOURNAL-CRMJ | Desember 2018}

terpengaruh oleh faktor-faktor harga, desain, lokasi, fasilitas, dan lingkungan. Kondisi ini dapat disebabkan antara lain karena konsumen sangat membutuhkan rumah untuk tempat tinggal pada saat itu.

Nilai koefisien regresi $\left(b_{1}\right)$ sebesar 0,267 , dan nilai probability (signifikansi) yang dihasilkan sebesar 0,026 lebih kecil daripada level of significance yang ditetapkan yaitu sebesar 0,05 . Nilai koefisien regresi dan hasil uji hipotesis tersebut, menunjukkan adanya hubungan searah yang signifikan antara harga rumah $\left(\mathrm{X}_{1}\right)$ dengan perilaku konsumen. Artinya semakin meningkat persepsi responden terhadap harga rumah di perumahan Purimas maka semakin meningkat pula perilaku konsumen untuk membeli rumah. Jadi setiap rupiah kenaikan harga rumah akan diikuti dengan perubahan perilaku konsumen dengan arah yang sama sebesar 0,267 kali.

Hubungan yang searah antara harga dan perilaku konsumen dalam keputusan membeli rumah tersebut tidak sejalan dengan teori atau hukum permintaan, dimana dalam teori permintaan antara harga dan permintaan bersifat berlawanan arah. Pertentangan tersebut terjadi tentu saja karena asumsi dasar Ceteris Paribus dalam hukum permintaan tersebut tidak terpenuhi, seperti Pendapatan konsumen berubah, selera berubah, kebutuhan semakin meningkat atau perubahan pada factor yang berpengaruh lainnya.

Nilai koefisien regresi $\left(b_{2}\right)$ sebesar 0,202 dan Nilai probability (signifikansi) yang dihasilkan sebesar 0,044 lebih kecil daripada level of significance yang ditetapkan yaitu sebesar 0,05 menunjukkan adanya hubungan yang searah dan signifikan antara desain rumah $\left(\mathrm{X}_{2}\right)$ dengan perilaku konsumen. Artinya semakin meningkat persepsi responden terhadap desain rumah di perumahan Purimas, maka semakin meningkat pula perilaku konsumen untuk membeli rumah. Jadi setiap satuan perubahan persepsi responden terhadap desain rumah akan diikuti dengan perubahan Perilaku Konsumen dalam keputusannya membeli rumah sederhana yang besarnya sama dengan 0,202 kali.

Disain rumah yang sesuai selera konsumen mempunyai pengaruh yang cukup signifikan, hal ini menunjukkan bahwa desain rumah dapat menciptakan ketertarikan kepada calon pembeli. Desain rumah dapat menimbulkan kesan mewah pada rumah sederhana, juga kelihatan seperti lebih luas, sirkulasi udara cukup, dan sinar matahari juga masuk ke dalam rumah. Desain rumah yang tepat yang mengikuti selera konsumen dan Trend yang sesuai dengan eranya, seperti Desain minimalis sangat cocok dengan selera konsumen saat ini, sehingga dapat dipahami kalau desain rumah ini dominasinya berada diurutan ketiga setelah harga dan factor lingkungan.

Nilai koefisien regresi $\left(b_{3}\right)$ sebesar 0,175 menunjukkan adanya hubungan yang searah antara lokasi perumahan $\left(\mathrm{X}_{3}\right)$ dengan perilaku konsumen.Sedangkan Nilai probability (signifikansi) yang dihasilkan sebesar 0,048 lebih kecil daripada level of significance yang ditetapkan yaitu sebesar 0,05 membuktikan adanya hubungan yang signifikan antara lokasi perumahan $\left(\mathrm{X}_{3}\right)$ dengan perilaku konsumen. Hubungan yang kuat dan signifikan tersebut mengindikasikan bahwa persepsi responden yang meningkat terhadap lokasi perumahan di perumahan 


\section{CREATIVE RESEARCH MANAGEMENT JOURNAL-CRMJ $\quad$ Desember 2018}

Purimas akan berdampak pada semakin meningkatnya perilaku konsumen untuk membeli rumah. Jadi setiap satuan perubahan persepsi responden terhadap lokasi perumahan akan diikuti dengan perubahan perilaku konsumen untuk membeli rumah.

Perumahahan yang lokasinya mudah dijangkau, atau lokasinya berdekatan dengan daerah perkantoran, tidak jauh pusat pendidikan, sekolah dan perguruan tinggi, dekat dengan pusat perekonomian dan sebagainya, menjadi daya pikat tersendiri bagi konsumen. Jadi semakin strategis lokasi suatu perumahan akan diikuti oleh perubahan positif dari perilaku konsumen dalam membeli rumah.

Nilai koefisien regresi $\left(b_{4}\right)$ sebesar 0,192 menunjukkan adanya hubungan yang searah antara fasilitas perumahan $\left(\mathrm{X}_{4}\right)$ dengan perilaku konsumen, dan Nilai probability (signifikansi) yang dihasilkan sebesar 0,038 lebih kecil daripada level of significance yang ditetapkan yaitu sebesar 0,05 . menunjukkan adanya hubungan yang signifikan antara fasilitas perumahan $\left(\mathrm{X}_{4}\right)$ dengan perilaku konsumen. Artinya semakin meningkat persepsi responden terhadap fasilitas di perumahan Purimas, maka semakin meningkat perilaku konsumen untuk membeli rumah tersebut. Jadi perilaku konsumen dalam membeli rumah sederhana akan berubah sebesar 0,192 mengikuti tiap satuan perubahan persepsi responden terhadap fasilitas di perumahan.

Fasilitas yang melekat pada rumah tersebut seperti listrik, air bersih, dan sebagainya, serta fasilitas lingkungan perumahan seperti fasilitas pendidikan, fasilitas kesehatan, tempat Ibadah, lapangan bermain dan fasilitas lainnya, menjadi bahan pertimbangan tersendiri bagi calon pembeli rumah, karena pada dasarnya fasilitas dari suatu perumahan sudah merupakan kebutuhan pokok bagi masyarakat sekitar. Jadi semakin lengkap fasilitas yang dimiliki suatu perumahan maka akan diikuti oleh perubahan perilaku konsumen dalam membeli rumah.

Nilai koefisien regresi $\left(b_{5}\right)$ sebesar 0,218 yang menunjukkan adanya hubungan yang searah antara lingkungan perumahan $\left(\mathrm{X}_{5}\right)$ dengan perilaku konsumen. Nilai probability (signifikansi) yang dihasilkan sebesar 0,041 lebih kecil daripada level of significance yang ditetapkan yaitu sebesar 0,05, menunjukkan adanya hubungan yang signifikan antara lingkungan perumahan $\left(\mathrm{X}_{5}\right)$ dengan perilaku konsumen untuk membeli rumah. Artinya semakin meningkat persepsi responden terhadap lingkungan perumahan di perumahan Purimas, maka semakin meningkat perilaku konsumen untuk membeli rumah. Setiap satuan perubahan persepsi konsumen terhadap Lingkungan perumahan akan diikuti dengan perubahan perilaku konsumen dalam membeli rumah sederhana sebesar 0,218 .

Lingkungan perumahan yang baik, kondisi kemanan yang kondusif, lingkungan yang bersih, hubungan social yang baik, kepedulian antar sesama warga perumahan tinggi, religius dan sebagainya, turut mempengaruhi perilaku konsumen dalam membeli rumah sederhana. 
Dengan membandingkan besaran koefisien Regresi dari masing masing Faktor Harga, Desain, Lokasi, Fasilitas yang tersedia dan Lingkungan, diketahui bahwa Faktor yang paling berpengaruh terhadap perilaku konsumen adalah harga rumah, kemudian lingkungan, Desain, dan selanjutnya Fasilitas yang tersedia serta lokasi perumahan.

Faktor harga menjadi factor yang paling dominan mempengaruhi perilaku konsumen dalam keputusan membeli rumah sederhana di Perumahan Purimas dimungkinkan karena menunjukkan masalah harga terkait dengan keterbatasan kemampuan konsumen untuk membeli rumah tersebut. Jadi walaupun Desain Rumah, lokasi, Fasilitas yang tersedia, serta Lingkungan Perumahan kurang sesuai dengan selera, tetapi karena kebutuhan akan rumah bersifat mendesak untuk dipenuhi maka factor factor yang terkait dengan selera ini bukan merupakan pertimbangan utama dalam perilaku konsumen.

\section{Kesimpulan dan Saran}

\section{Kesimpulan}

a. Berdasarkan analisa Korelasi berganda Variabel Harga, Desain Rumah, lokasi, Fasilitas yang tersedia, serta Lingkungan Perumahan secara simultan berpengaruh sangat kuat terhadap perilaku konsumen dalam keputusan membeli rumah sederhana di Perumahan Purimas sebagaimana ditunjukkan oleh hasil koefisien korelasi berganda (R) 0,929, dengan besarnya kontribusi variasi perubahan ke lima variable indipenden tersebut terhadap perilaku konsumen sebesar $86,3 \%$.

b. Berdasarkan analisa Regresi berganda $Y=0,079+0,267 X_{1}+0,202 X_{2}+$ $0,175 \mathrm{X}_{3}+0,192 \mathrm{X}_{4}+0,218 \mathrm{X}_{5}+\mathrm{e}_{1}$ menghasilkan Variable yang lebih dominan berpengaruh terhadap perilaku konsumen adalah harga rumah, kemudian diikuti oleh lingkungan, Desain dan selanjutnya Fasilitas yang tersedian serta lokasi perumahan.

c. Hasil Uji Hipotesis terhadap koefisien korelasi berganda menunjukkan bahwa Dengan $\alpha=0,05$, hubungan antara Harga, Desain Rumah, lokasi, Fasilitas yang tersedia, serta Lingkungan Perumahan secara simultan berpengaruh secara signifikan terhadap perilaku konsumen dalam keputusan membeli rumah sederhana di Perumahan Purimas Kota Bengkulu.

d. Hasil Uji Hipotesis terhadap koefisien regresi dari kesemua variable Yang diteliti juga menunjukkan pengaruh yang signifikan, yang ditunjukkan oleh nilai signifikansi masing masing variable lebih kecil dari pada $\alpha=0,05$.

\section{Saran}

Berdasarkan analisis tersebut peneliti menyarankan kepada CV. Bakti Nusa Development selaku pengembang untuk mempertahankan Harga, menciptakan Disain baru yang mengikuti selera pasar, serta meningkatkan fasilitas perumahan. 


\section{CREATIVE RESEARCH MANAGEMENT JOURNAL-CRMJ}

\section{DAFTAR PUSTAKA}

- Effendi, Rustam, 1988, Pengantar Marketing Manajemen, IKIP Malang

- Engel, J.F. et.al. 1994. Consumer Behavior Jilid 1, Alih Bahasa Budiyanto. Jakarta: Binarupa Aksara.

- Hamzah, Andi, 1992, Dasar-Dasar Hukum Perumahan, Rineka Cipta, Jakarta

- Kotler, Philip dan Kevin Lane Keller. 2008. Manajemen Pemasaran, Jilid 1. Jakarta: Erlangga.

- Swastha, Basu, 2000. Pengantar Bisnis Modern, Pengantar Ekonomi Perusahaan Modern. Jakarta: Liberty

- Swastha, Basu, dan T. Hani Handoko. 2000. Manajemen Pemasaran (Analisa Perilaku Konsumen). Yogyakarta: BPFE UGM.

- https://www.maxmanroe.com/vid/bisnis/pengertian-harga.html

- $\quad$ http://ciputrauceo. net/blog/2015/6/11/perilaku-konsumen

- http://seputarpengertian.blogspot. com/ 2017/05/pengertian-lingkungan-sertajenisnya.html

- http://www.pengertianmenurutparaahli.net/pengertian-fasilitas/

- http://www.haidesain.com/2017/11/pengertian-desain-menurut-para-ahli.html 